\title{
ABDOMINAL HYSTERECTOMY: A COMMON SURGICAL PROCEDURE FOR BENIGN GYNAECOLOGICAL DISEASE
}

\author{
Meharunnissa Khaskheli and Shahla Baloch
}

\begin{abstract}
OBJECTIVES: To analyze the pattern of abdominal hysterectomies in our set up with regard to cause, type and complications associated with this procedure.

DESIGN: A descriptive study.

SETTING: Department of Gynaecology and Obstetrics (Units II and IV), Liaquat University Hospital Hyderabad/ Jamshoro, Sindh - Pakistan; from March 2002 to December 2005.

PATIENTS AND METHODS: Patients were women between 35 and 55 years of age in whom hysterectomy was done for benign lesions. Data was collected through a pre-designed proforma.

RESULTS: Total number of patients admitted during study period at the department were 3519, of which $1684(47.85 \%)$ had the gynaecological disease. Of these 1684 patients, $776(46.08 \%)$ required surgery. Majority of these women (61.86\%) were in age group 30-40 years. Two hundred eighty-seven women undergone major surgery which included abdominal hysterectomy in 127 (44.25\%) cases. Leiomyoma was the main cause for abdominal hysterectomy. Total abdominal hysterectomy only was performed in 78 (61.41\%) cases. Immediate complications associated with surgery were rare while pelvic pain was more frequent late complication.

CONCLUSION: Hysterectomy rate is high in our set up and is commonly performed for benign lesions.
\end{abstract}

KEY WORDS: Hysterectomy. Benign lesion. Malignancy. Leiomyoma. Pakistan.

\section{INTRODUCTION}

Hysterectomy is the commonest gynaecological operation $^{1}$. It was first performed in 1507 by Berengarius of Bolonga through vaginal route. But the credit for first vaginal hysterectomy was given to Langen back in 1813. The first total abdominal hysterectomy with bilateral salpingo-oophrectomy was done by Clay in 1844. Hysterectomy rate varies according to geographic distribution, patient and physician related factors $^{1}$. It is still considered as the treatment of choice for benign lesions such as myomas, adenomyosis, extensive pelvic infection or adhesions, dysfunctional uterine bleeding (DUB) and obstetric complications. Its ratio is still 1 in 5 cases in women in United Kingdom at some stage of their life. DUB affects $20-30 \%$ of women and $60 \%$ of women having this problem undergo hysterectomy ${ }^{2-3}$. In Pakistan, the rate of hysterectomy is quite high because it is the only surgical option available if patient is not responding to medical treatment. However, hysterectomy has major drawbacks and is associated with high morbidity and mortality. Other surgical treatment options like endometrial laser ablation (ELA), transcervical resection of endometrium (TCRE) and uterine artery embolization are widely practised as conservative surgical treatment for benign gynaecological conditions in other countries but in our country, they are not widely available for the non-availability of newer techniques. Hysterectomy continues to be the major treatment for benign gynaecological disease. The rationale of this study was to find out the common gynaecological conditions in which hysterectomy is done and to explore other methods which are less invasive and with low morbidity and mortality.

\section{PATIENTS AND METHODS}

A retrospective medical record analysis of all hysterectomies performed during March 2002 to December 2005 in Gynaecology and Obstetrics (Units II and IV) of Liaquat University Hospital Hyderabad/Jamshoro was carried out. Liaquat University Hospital is a major health care facility of Sindh province of Pakistan which caters services to most of the population of Sindh excluding Karachi city. All the women in whom hysterectomy was done for benign gynaecological lesions were included in the study. Exclusion criteria included women with malignancies, uterovaginal prolepse, caesarean hysterectomies, etc. A proforma was designed to collect and analyse the data regarding history, clinical examination, investigations, surgical procedure, complications, histopathological findings and follow up status. All the data were analysed through SPSS version 10.0.

\section{RESULTS}

Total number of patients admitted during study period 
were 3519, of which, 1684 (47.85\%) had the gynaecological disease. Of these 1684 patients, 776 (46.08\%) required surgery. Majority of these women (61.86\%) were in age group 30-40 years while others in age group of 40-50 years. Minor surgical procedures like $D \& C, D \& E$ and biopsy were performed in majority $(63.01 \%)$ of the cases while other undergone major surgery. Two hundred eighty seven women undergone major surgery. It included abdominal hysterectomy in 127 (44.25\%) cases, laparotomy for mass, adhesiolysis, torsion ovarian cyst, chocolate cyst, endometriosis, pyosalpinx in $88(30.66 \%)$ cases, vaginal hysterectomy in $48(16.72 \%)$ and Manchester repair in $24(8.36 \%)$ cases respectively. Leimyoma was the main cause for abdominal hysterectomy followed by DUB, malignant disease and adenomyosis (Table I). Total abdominal hysterectomy only was performed in 78(61.41\%) cases (Table II). Immediate complications associated with surgery were rare while pelvic pain was more frequent as late complication (Table III).

TABLE I:

CAUSES FOR ABDOMINAL HYSTERECTOMY $(n=127)$

\begin{tabular}{|l|c|c|}
\hline \multicolumn{1}{|c|}{ Lesion } & $\begin{array}{c}\text { Number of } \\
\text { Patients }\end{array}$ & Percentage \\
\hline Leiomyoma & 48 & 37.79 \\
\hline DUB & 45 & 35.43 \\
\hline Adenomyosis & 6 & 4.72 \\
\hline $\begin{array}{l}\text { Other causes } \\
\text { (Carcinomas of cervix } \\
\text { and ovary and endo- } \\
\text { metrium) }\end{array}$ & 24 & 8.36 \\
\hline
\end{tabular}

TABLE II:

DISTRIBUTION OF ABDOMINAL HYSTERECTOMY WITH OR WITHOUT OOPHRECTOMY $(n=127)$

\begin{tabular}{|l|c|c|}
\hline $\begin{array}{l}\text { Hysterectomy with or } \\
\text { without oophrectomy }\end{array}$ & $\begin{array}{c}\text { Number of } \\
\text { Patients }\end{array}$ & Percentage \\
\hline $\begin{array}{l}\text { Total abdominal hysterec- } \\
\text { tomy only }\end{array}$ & 78 & 61.41 \\
\hline $\begin{array}{l}\text { Total abdominal hysterec- } \\
\text { tomy with unilateral } \\
\text { salpingo-oophrectomy }\end{array}$ & 28 & 22.04 \\
\hline $\begin{array}{l}\text { Total abdominal hysterec- } \\
\text { tomy with bilateral } \\
\text { salpingo-oophrectomy }\end{array}$ & 21 & 16.53 \\
\hline
\end{tabular}

TABLE III:

COMPLICATIONS ASSOCIATED WITH SURGERY $(n=127)$

\begin{tabular}{|c|c|c|}
\hline Complication & $\begin{array}{c}\text { Number of } \\
\text { Patients }\end{array}$ & Percentage \\
\hline \multicolumn{3}{|l|}{ Immediate } \\
\hline Anaesthesia & 2 & 1.57 \\
\hline Hemorrhage & 1 & 0.78 \\
\hline \multicolumn{3}{|l|}{ Late } \\
\hline Pyrexia & 15 & 11.81 \\
\hline UTI & 6 & 7.72 \\
\hline Chest infections & 8 & 6.29 \\
\hline Wound haematoma & 25 & 19.68 \\
\hline Pelvic pain & 30 & 23.62 \\
\hline
\end{tabular}

\section{DISCUSSION}

DUB affects $20-30 \%$ of women, accounts for $12 \%$ of gynaecological referral ${ }^{2,4}$ and within 5 years of referral, $60 \%$ of women will have to undergo hysterectomy ${ }^{3}$ making it the commonest major gynaecological problem. In this study, $35.53 \%$ had hysterectomy due to DUB. The high rate of hysterectomies due to DUB in our set up could be because of non compliance with medical therapy and non-availability of minimal invasive techniques for the treatment of DUB. Even in advanced countries, medical treatment is effective in $50 \%$ of women ${ }^{5}$. The hysterectomy has high rate of satisfaction and is the definitive treatment but now the ablative methods are preferred due to shorter hospital stay and quick return to full activities. These techniques have been extensively evaluated in randomised trials ${ }^{6-9}$. Based on these trials, endometrial ablative techniques have been given grade $A$ recommendation by the Royal College of Obstetricians and Gynaecologists for the treatment of heavy menstrual bleeding ${ }^{10}$. Other common indication for which hysterectomy was done in our set up, was the Leiomyoma (37.79\%). Majority of patients in this study were more than 35 years of age, had completed family and preferred this operation due to their long lasting symptoms, poverty and recurrent nature of the fibroids after myomectomy. Same finding is reported in the study conducted at Khyber Hospital, NWFP - Pakistan where hysterectomy for fibroids was done mostly in multiparous women ${ }^{11}$. The uterine artery embolisation 
was first advocated as a treatment for uterine fibroids $^{12}$. It is less invasive option for those who want to conserve uterus but in our public sector set up, these facilities are not available. In this study, 4.72\% patients had hysterectomy for adenomyosis as this is the definitive treatment for it. Adenomyosis may present with symptoms similar to uterine fibroids but usually the diagnosis is made post operatively on the basis of histopathology. Although, embolization has been advocated for adenomyosis but no data suggest that embolisation is effective in this condition. In this study, operative complications were in the form of haemorrhage $(0.75 \%)$ and anaesthesia (1.57\%). Post operative complications included infections like urinary tract infection $7.72 \%$, chest infection $6.29 \%$, pyrexia $11.81 \%$ etc. The commonest complication was infection which can be due to poor resistance and long lasting anaemia due to menstrual irregularities and poverty in our population. Meanwhile, in a Swedish study for gynaecological surgery, the risk factors for infection were non use of prophylactic antibiotics under 40 years and obesity ${ }^{13}$. Late complications were pelvic pain (23.62\%) and psychological disturbances (18.11\%) like depression, insomnia, and dyspareunia 3 to 6 months post operatively. They were given symptomatic treatment, reassurance and sympathetic support. These psychological disturbances were more common in women who had pre-operative depression about their problems and anxiety about surgery. Same had been reported by Gath $D$, et al. and Martin RL, et al. ${ }^{14-15}$ but counselling and proper selection of patients for surgery improves the problem ${ }^{16}$.

\section{CONCLUSIONS}

Hysterectomy rate is high in our set up and is associated with high morbidity. Hence, it is recommended that modern techniques (second generation) like endometrial ablation including resection and uterine artery embolisation should be introduced in health care set ups as ours. Further studies shall also be carried out to compare different treatment options in our setup.

\section{REFERENCES}

1. Vessey MP, Villard-Mackintosh L, McPherson K, Coulter A, Yeats D. The epidemiology of hysterectomy: findings in a large cohort study. $\mathrm{Br} \mathrm{J}$ Obstet Gynecol. 1992; 99:402-7.

2. Cooke I, Lethaby A, Farquhar C. Antifibrinolytic for heavy menstrual bleeding (Cochrane review). In: The Cochrane Library, Issue 3. Oxford; Updated Softwares, 1999.

3. Coulter A, Bradlow J, Agass M, Martin-Bates C, Tulloch A. Outcomes of referrals to gynaecology outpatient clinics for menstrual problems: an audit of general practice records. $\mathrm{Br} \mathrm{J}$ Obstet Gynaecol. 1991;98(8):789-96.

4. Cooper KG, Parkin DE, Garret AM, Grant AM. A randomised comparison of medical and hysteroscopic management in women consulting a gynaecologist for treatment of heavy menstrual loss. Br J Obstet Gynaecol. 1997; 104:1360-6.

5. Serial and cross-over studies in the treatment of dysfunctional uterine bleeding with tranexamic acid, mefanamic acid and ethamsylate. In Bonnarj, Smith SK (eds) Dysfunctional uterine bleeding. London: Royal Society of Medicine Press, 1994: Pp. 102-103.

6. Pinion SB, Parkin DE, Abramovich DR, et al. Randomised trial of hysterectomy, endometrial laser ablation and transcervical resection of the endometrium for dysfunctional uterine bleeding. $\mathrm{Br}$ Med J. 1994; 309: 979-83.

7. Aberdeen Endometrial Ablation Trials Group. A randomised trial of endometrial ablation versus hysterectomy for the treatment of dysfunctional uterine bleeding: outcome at four years. $\mathrm{Br} \mathrm{J} \mathrm{Ob-}$ stet Gynecol. 1999; 106: 360-66.

8. Gannon MJ, Holt EM, Fairbank J, et al. A randomised trial comparing endometrial resection and abdominal hysterectomy for the treatment of menorrhagia. Br Med J. 1991; 303: 1362-4.

9. Dwyer N, Hutton J, Stirrat GM. Randomised controlled trial comparing endometrial resection with abdominal hysterectomy for the surgical treatment of menorrhagia. Br J Obstet Gynecol. 1993; 100: 237-43.

10. Royal College of Obstetricians and Gynaecologists. The management of menorrhagia in secondary care. Evidence based clinical guidelines No.5, London: RCOG, 1995.

11. Begum S, Khan S. Audit of leiomyoma uterus at Khyber Teaching Hospital, Peshawar. J Ayub Med Coll Abbottabad. 2004; 16 (2): 46-9.

12. Ravina JH, Bouret JM, Fried D, et al. Value of pre operative embolisation of a uterine fibroma: report of a multi- centre series of 31 cases. Contracept Fertil Sex. 1995; 23:45-49. 
13. Lofgren M, Poromaa IS, Stjerndahl JH, Renstrom B. Post operative infections and antibiotic prophylaxis for hysterectomy in Sweden: Study by the Swedish national register for gynaecologic surgery. Obstet Gynecol Surv. 2005; 60 (3):168-9.

14. Gath D, Osborn M, Bungay G, et al. Psychiatric disorders and gynaecological symptoms in middle aged women; a community survey. $\mathrm{Br}$ Med $\mathrm{J}$.
1987: 294; 213-18.

15. Martin RL, Roberts WV, Clayton PJ. Psychiatric status after hysterectomy; one year prospective follow-up. J Am Med Assoc. 1960: 244: 350-53.

16. Ryan MM. Hysterectomy: social and psychological aspects. Ballieres Clin Obstet Gynaecol. 1997; 11: 23-36.

AUTHOR AFFILIATION:

Dr. Meharunnissa Khaskheli (Corresponding Author) Assistant Professor

Department of Gynaecology and Obstetrics (Unit-IV)

Liaquat University of Medical \& Health Sciences

(LUMHS) Jamshoro, Sindh - Pakistan.

Email: drmehar1964@yahoo.com

Dr. Shahla Baloch

Senior Registrar,

Department of Gynaecology and Obstetrics (Unit-II)

LUMHS Jamshoro, Sindh - Pakistan. 